\title{
Developmental expression of inhibitory synaptic long-term potentiation in the lateral superior olive
}

\author{
Vibhakar C. Kotak ${ }^{1}$ and Dan H. Sanes ${ }^{1,2 *}$ \\ ' Center for Neural Science, New York University, New York, NY, USA \\ 2 Department of Biology, New York University, New York, NY, USA
}

\section{Edited by:}

Conny Kopp-Scheinpflug,

Ludwig-Maximilians-University

Munich, Germany

Reviewed by:

Gina Turrigiano, Brandeis University,

USA

George Spirou, West Virginia

University, USA

*Correspondence:

Dan H. Sanes, Center for Neural

Science, 4 Washington Place, New York University, New York, NY,

10003, USA

e-mail:dhs1@nyu.edu
Principal neurons of the lateral superior olivary nucleus (LSO) respond selectively to interaural level differences (ILD). To perform this computation, LSO neurons integrate excitatory synaptic drive from the ipsilateral ear with inhibitory synaptic drive from the contralateral ear via the medial nucleus of the trapezoid body (MNTB). Previous research demonstrated that inhibitory terminals from the MNTB to the LSO are eliminated during development. Furthermore, MNTB synapses display an activity- and age-dependent long-term depression (iLTD) that may contribute to inhibitory synapse elimination. However, inhibitory synapses that are stabilized become stronger. Here, we asked whether MNTB synapses displayed activity-dependent strengthening. Whole-cell recordings were obtained from LSO neurons in a gerbil brain slice before and after hearing onset. The inhibitory MNTB afferents were stimulated at a low rate, similar to spontaneous discharge rates observed in vivo. The MNTB-evoked inhibitory responses were strengthened by $40-300 \%$ when synaptic activity was coupled with postsynaptic membrane depolarization, exogenous glutamate application, or activation of ipsilateral excitatory synaptic inputs. This inhibitory long-term potentiation (iLTP) was associated with increased spontaneous inhibitory postsynaptic current (IPSC) amplitude and frequency. One hour after iLTP induction, IPSCs could not be de-potentiated by the MNTB stimulation pattern that induces iLTD in control slices. iLTP could only be induced after hearing onset (>P12), and was blocked in the presence of a $\mathrm{GABA}_{B}$ receptor antagonist. Together, these results suggest a developmental period during which the induction of iLTP depends on the conjoint activation of $\mathrm{GABA}_{B}$ receptors and postsynaptic depolarization. We propose that iLTP may support stabilization of un-pruned MNTB connections and contribute to the emergence of ILD processing in the mature LSO.

\section{Keywords: GABA, glycine, GABA ${ }_{B}$, synaptic potentiation, plasticity, LSO}

\section{INTRODUCTION}

The encoding of sound localization cues, such as interaural level (ILD) and time differences (ITD), begins in the ventral auditory brain stem. For ILD coding, the discharge rate of lateral superior olivary (LSO) neurons is proportional to the integration of ipsilateral excitatory drive arising from the cochlear nucleus and contralateral inhibitory drive from the medial nucleus of the trapezoid body (MNTB) (Boudreau and Tsutchitani, 1968; Caird and Klinke, 1983; Harnischfeger et al., 1985; Tollin, 2003; Sterenborg et al., 2010). The inhibitory MNTB afferents form a tonotopic projection in the LSO that is aligned precisely with the ipsilateral excitatory projection in the adult (Sanes and Rubel, 1988). Furthermore, this precision evolves as inhibitory synapses are eliminated during postnatal development (Sanes and Siverls, 1991; Sanes and Friauf, 2000; Kim and Kandler, 2003; Kandler, 2004; Kandler and Gillespie, 2005; Kandler et al., 2009). A similar elimination of inhibitory MNTB terminals occurs at the medial superior olivary nucleus, which encodes ITD (Kapfer et al., 2002), although one study did not find a significant developmental change in amplitude (Walcher et al., 2011). It is, therefore, plausible that that the establishment of properly aligned excitatory and inhibitory maps involves the dynamic addition and elimination of inhibitory synapses. One mechanism that could participate in synapse elimination, inhibitory long-term depression (iLTD), has been described previously for MNTB synapses (Kotak and Sanes, 2000, 2002; Kotak et al., 2001; Chang et al., 2003). As inhibitory synapses are eliminated and the remaining contacts are strengthened in the rat LSO, there is a 12 -fold increase in inhibitory conductance (Kim and Kandler, 2003). Here, we describe a mechanism that could account for this strengthening.

A vast literature on excitatory long-term potentiation (LTP) and depression (LTD) in the hippocampus and neocortex supports their involvement in adult learning, memory and neurodevelopmental disorders (see Bear and Malenka, 1994; Bliss et al., 2013). Many studies have also shown that inhibitory synapses can be strengthened or weakened in an activitydependent manner. However, the functional consequence of such 


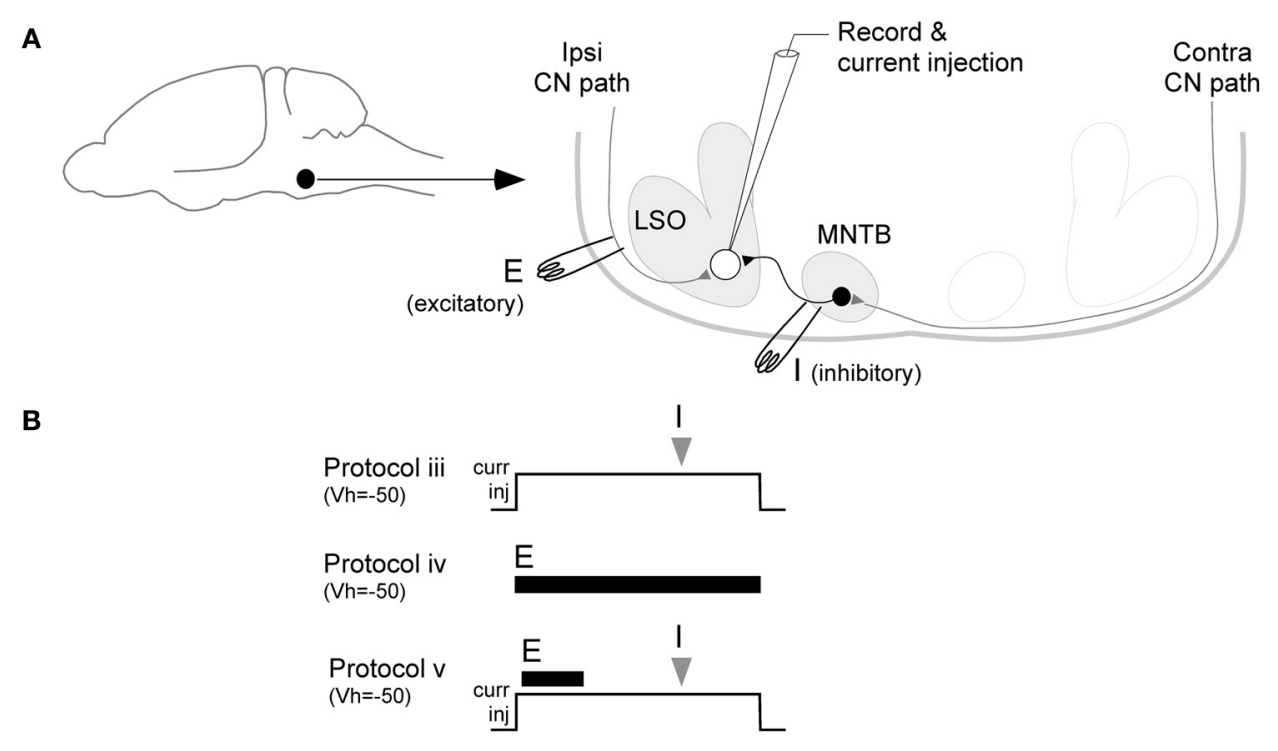

C
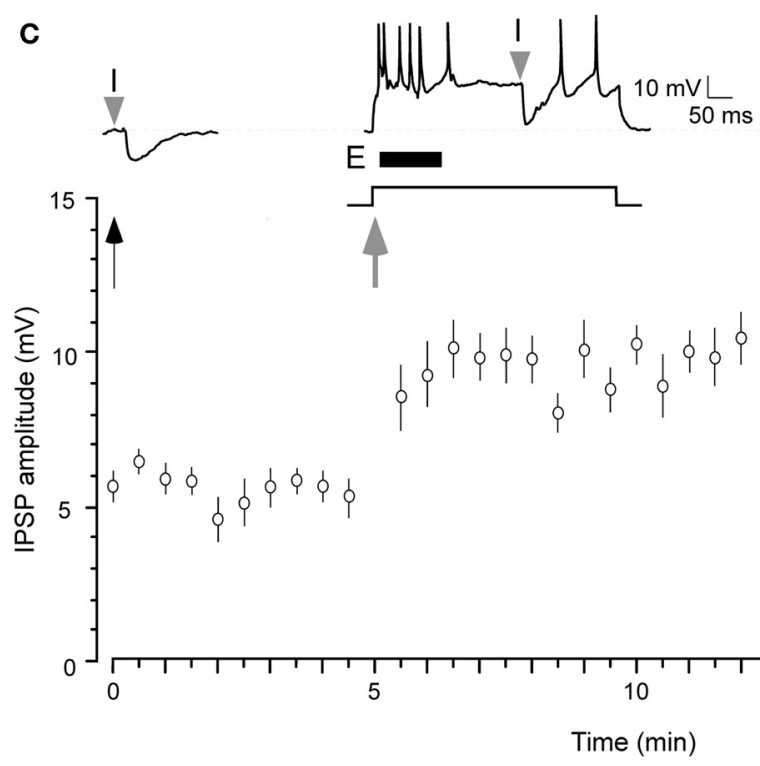

FIGURE 1 | laqnduction of inhibitory LTP in P12-15 day neurons. (A) A schematic of the LSO circuit in brain slice preparation. Filled circle and arrow indicate auditory brainstem. E: ipsilateral excitatory pathway from cochlear nucleus (CN), I: MTNB pathway activated by contralateral CN. (B) Three of the stimulus protocols are shown (see Results for details). Only Protocol $v$ was effective in inducing iLTP, as shown in (C). (C) A pre-conditioning MNTB-evoked IPSP evoked by MNTB stimulus (I). Such IPSPs were obtained at $0.033 \mathrm{~Hz}$ for $5 \mathrm{~min}$ at $V_{\text {HOLD }}=-50 \mathrm{mV}$ (baseline). A single suprathreshold depolarization $(500 \mathrm{~ms},+5-10 \mathrm{pA})$ injection was used to trigger neuronal firing by up to $50 \mathrm{~Hz}$. The ipsilateral excitatory afferents were then stimulated at $100 \mathrm{~Hz} 10 \mathrm{~ms}$ after the onset of $500 \mathrm{~ms}$ depolarization (10 pulses, dark bar under the trace, E). MNTB evoked IPSP was timed at $300 \mathrm{~ms}$ after the injection of the $500 \mathrm{~ms}$ depolarizing pulse (gray arrowhead). The $0.033 \mathrm{~Hz}$ acquisition of IPSP was continued through the recording session. IPSPs displayed a significant enhancement in amplitude for at least $20 \mathrm{~min}$ (top right trace $20 \mathrm{~min}$ after). Bottom panel shows summary data (mean \pm s.e.m.). In 4 neurons, recordings were continued for an additional $40 \mathrm{~min}$, and the increased amplitude IPSPS persisted. IPSP means ( $Y$ axis) are sub-maximum amplitude and not normalized. inhibitory synapse plasticity and the underlying biochemical and molecular factors are not well understood. Inhibitory plasticity, including GABAergic LTP and LTD, may contribute to memory formation or motor learning (Morishita and Sastry, 1996; Aizenman et al., 1998; Ouardouz and Sastry, 2000). Glycinergic LTP at the goldfish Mauthner neuron may dampen the escape response (Oda et al., 1995, 1998), and GABAergic LTP in the visual cortex may alter visual coding properties (Komatsu and Iwakiri, 1993; Komatsu, 1994, 1996; Komatsu and Yoshimura, 2000). Since MNTB-mediated iLTD gradually wanes following hearing onset (Kotak and Sanes, 2000), it is possible that iLTP emerges during this time. Our results demonstrated that even very low levels of inhibitory afferent activity, when coupled with excitatory transmission, can trigger iLTP after hearing onset. 


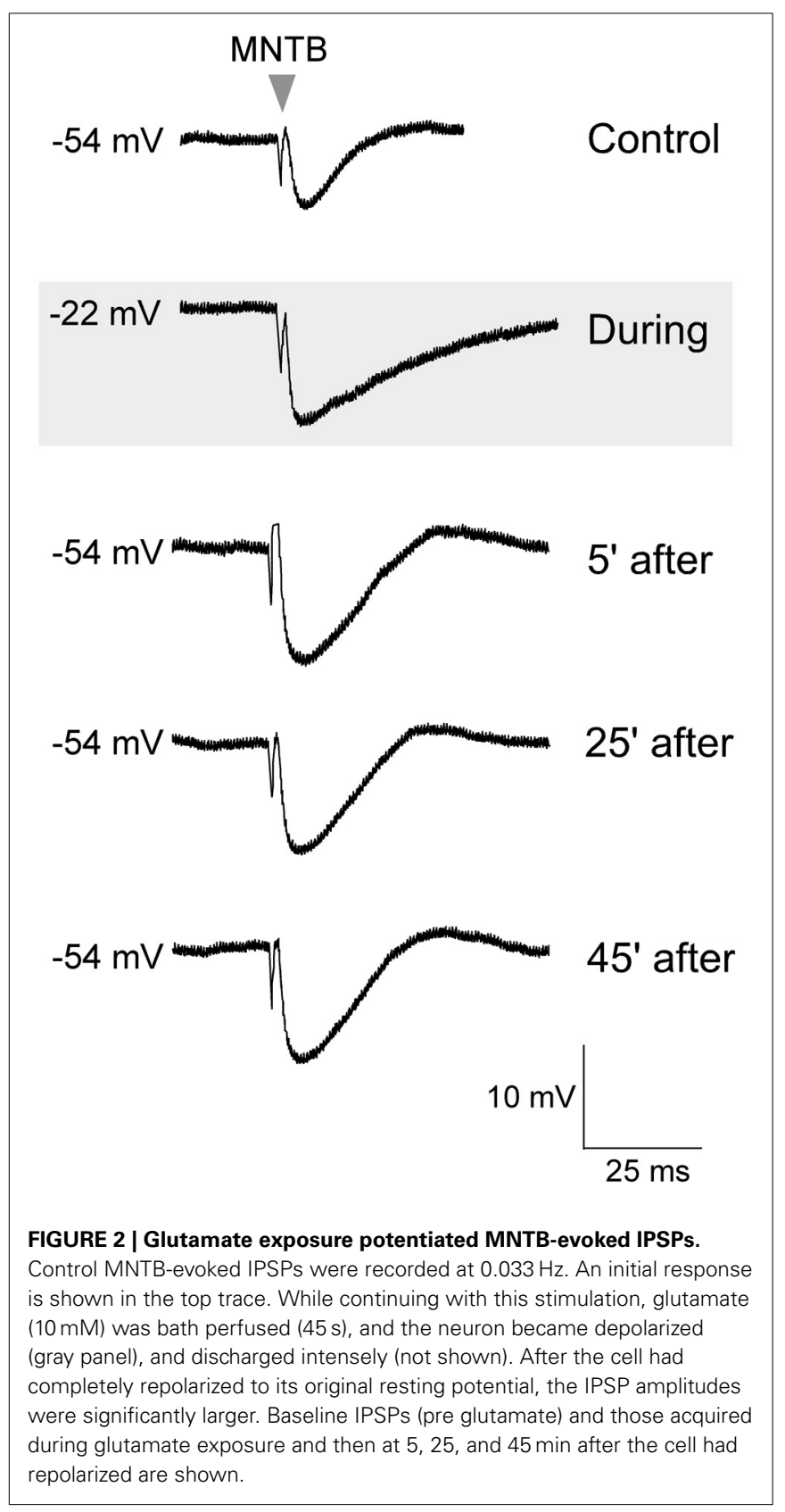

Thus, early binaural cues may be critical in consolidating the functional maturation of LSO inhibitory synapses.

\section{MATERIALS AND METHODS}

All protocols were reviewed and approved by the New York University Institutional Animal Care and Use Committee. Gerbil pups (Meriones unguiculatus) aged postnatal $(\mathrm{P})$ days $7-15$, were used to generate $300 \mu \mathrm{m}$ transverse brain slices containing the MNTB-LSO circuit (Sanes, 1993). The artificial cerebrospinal fluid (ACSF) contained (in mM): $125 \mathrm{NaCl}, 4 \mathrm{KCl}, 1.2 \mathrm{KH}_{2} \mathrm{PO}_{4}$, $1.3 \mathrm{MgSO}_{4}, 24 \mathrm{NaHCO}_{3}, 15$ glucose, $2.4 \mathrm{CaCl}_{2}$, and 0.4 L-ascorbic acid ( $\mathrm{pH}=7.3$ when bubbled with $95 \% \mathrm{O}_{2} / 5 \% \mathrm{CO}_{2}$ ). ACSF was continuously superfused in the recordingchamber at
$3 \mathrm{ml}$ per min at $32 \pm 1^{\circ} \mathrm{C}$. Whole-cell current clamp or voltage or recordings were obtained from LSO neurons (Warner PC-501A) and $200 \mu$ s current pulses were delivered directly to the MNTB via bipolar stimulating electrodes to elicit IPSPs or IPSCs, respectively (Kotak et al., 1998). Ipsilateral excitatory afferents were stimulated by a separate bipolar stimulating electrodes at specific frequencies (Results) (Figure 1). Recording electrodes were fabricated from borosylicate glass microcapillaries $(1.5 \mathrm{~mm}$ OD), and when filled with internal solution the resistance was 5-15 $\mathrm{M} \Omega$. For current clamp recordings, the internal patch solution contained (in $\mathrm{mM}$ ): $127.5 \mathrm{mM}$ potassium gluconate, 0.6 EGTA, 10 HEPES, $2 \mathrm{MgCl}_{2} 5 \mathrm{KCl}, 2 \mathrm{ATP}$, and $0.3 \mathrm{GTP}$. For both internal solutions, the $\mathrm{pH}$ of was adjusted to 7.2 with $\mathrm{KOH}$. For voltage clamp recordings, the internal solution was similar to current clamp solution (follows) except potassium gluconate was replaced by an equimolar concentration of cesium gluconate to block voltage-dependent potassium channels, and QX-314 $(5 \mathrm{mM})$ was added to block voltage-dependent sodium channels. The $\mathrm{pH}$ was adjusted to 7.2 with $\mathrm{CsOH}$. Further, kynurenic acid $(4 \mathrm{mM})$ was added to the ACSF to block ionotropic glutamate receptors (Moore et al., 1998). Access resistance was balanced throughout the recordings and ranged between 10 and $40 \mathrm{M} \Omega$.

All data were collected using a Macintosh G4 platform running a Mac OS X compatible custom IGOR (WaveMetrics, v3.5) macro called SLICE. The data were analyzed off-line using a second IGOR macro called SLICE ANALYSIS (Kotak et al., 2001). Custom algorithms were used to measure the amplitude and frequency of sIPSCs (Kotak et al., 2005). Data values are presented as mean and standard error of the mean (SEM). Initial IPSP/IPSC amplitudes were compared vs. IPSC amplitudes at the end of the recording session with a non-parametric test (Wilcoxon; Kotak and Sanes, 2000). All statistical analyses were performed using the SAS-based statistical software (JMP v5.0).

\section{RESULTS}

The data in this paper were collected from 60 principal neurons from 42 animals located in the high frequency medial limb of the LSO, each from a separate brain slice. We first asked whether iLTP could be induced under normal physiological conditions in a brain slice preparation without any intracellular or pharmacological manipulations. These current clamp recordings were similar to those employed for the induction of iLTD as described previously (Kotak and Sanes, 2000) except the stimulation rates and postsynaptic depolarization was different.

\section{CURRENT CLAMP RECORDINGS}

First, to determine whether IPSPs recorded in current clamp without glutamate receptor antagonists exhibited any change in strength, we attempted the following protocols. The stimulus to evoked IPSPs was first calibrated to evoke an IPSP at 50\% of its maximum amplitude. This enabled us to observe the possible expression of either potentiation or depression. To do this, MNTB was stimulated in incremental intensity $(200 \mu \mathrm{s}, 5 \mu \mathrm{A}$ increments) until maximum amplitude IPSP was obtained. We then selected the stimulus intensity that evoked an approximately $50 \%$ maximum amplitude ( $200 \mu \mathrm{s}, \sim 80-90 \mu \mathrm{A}$ ). 
Protocol i: IPSPs were recorded at a rate of $0.033 \mathrm{~Hz}$ for approximately $1 \mathrm{~h}$. Under this condition, no change in amplitude was observed (initial IPSP amplitude: $7.4 \pm 0.8 \mathrm{mV}$ vs. IPSP amplitude at $60 \mathrm{~min}: 6.3 \pm 0.7 \mathrm{mV} ; t=2.1, p>0.05 ; n=7)$. Protocol ii: Our next step was to test MNTB stimulation rates of 0.1 or $5 \mathrm{~Hz}$. These rates were dissimilar to the rate that produced iLTD $(1 \mathrm{~Hz}, 15 \mathrm{~min})$ in our previous study. Under these conditions, no significant change in IPSP amplitude was observed for up to $10 \mathrm{~min}$ (not shown). Protocol iii: LSO neurons were held slightly more depolarized (at $-50 \mathrm{mV}$ ) than their resting membrane potential (ranged between -51 and $-55 \mathrm{mV}$ ) by injection of a small DC current ( $+5-10 \mathrm{pA})$. This provided a steady membrane potential baseline against which inhibitory strength could be recorded. In addition, a suprathreshold depolarization ( $500 \mathrm{~ms}$ ) was used to increase neuronal firing by up to $50 \mathrm{~Hz}$, a firing rate that may elevate intracellular calcium to support induction of iLTP. Furthermore, a single MNTB-evoked IPSP was timed to occur $300 \mathrm{~ms}$ after the onset of postsynaptic depolarization. This regimen was ineffective in triggering iLTP $(n=4$, not shown). Protocol iv: To test whether glutamatergic transmission was sufficient to induce iLTP, ipsilateral excitatory afferents were stimulated at $20 \mathrm{~Hz}$ (10 pulses) while cells were held at $-50 \mathrm{mV}$. This protocol did not induce a significant change in IPSP amplitude $(n=4$, not shown). Since each of these protocols was ineffective, we predicted that the induction of iLTP would require a greater level of postsynaptic glutamate receptor activation.

The protocol that proved to be effective, involved a combination of the above manipulations. Protocol v: Cells were held at $-50 \mathrm{mV}$ and a single $500 \mathrm{~ms}$ postsynaptic depolarization to induce up to $50 \mathrm{~Hz}$ firing was elicited with current injection.
An increased level of ipsilateral excitatory afferent stimulation $(100 \mathrm{~Hz}, 10$ pulses) was timed to occur $10 \mathrm{~ms}$ after the onset of this depolarization. Lastly, MNTB stimulation was timed to occur $300 \mathrm{~ms}$ after the onset of the $500 \mathrm{~ms}$ postsynaptic depolarization (Figure 1, top panel). Under these conditions, IPSPs were potentiated for $20 \mathrm{~min}$ or longer (Figure 1C; initial IPSP amplitude: $5.9 \pm 0.3 \mathrm{mV}$, IPSP amplitude $20 \mathrm{~min}$ after conditioning: $10.1 \pm 0.6 \mathrm{mV}$; Wilcoxon test, $X^{2}=3.9, p=0.001, n=7$ ). In 4 of these cases, when the recording session was extended, increased IPSP amplitude persisted for $1 \mathrm{~h}$ after the conditioning protocol $(9.7 \pm 1.95 \mathrm{mV})$.

To test whether such co-activation of ipsilateral excitatory afferents could have involved postsynaptic activation of glutamate receptors to induce iLTP, in separate experiments, glutamate was bath applied $(10 \mathrm{mM}, 45 \mathrm{~s})$ in the absence of ipsilateral afferent stimulation (Kotak and Sanes, 1995). Thus, this protocol was designed to bypass the possible co-recruitment of ipsilaterally evoked inhibition (Kotak and Sanes, 1997). Sub-maximum IPSPs were first elicited for $10 \mathrm{~min}$ to establish a baseline, before the application of glutamate. Glutamate treatment depolarized the LSO neurons from none to by up to $20 \mathrm{mV}$, and increased the discharge rate of recorded neurons from none up to $50 \mathrm{~Hz}$. The MNTB stimulation was maintained during this depolarization for $30 \mathrm{~min}$ and MNTB stimulation continued after the cells had returned to the starting $V_{\text {REST }}$. As shown in Figure 2, when IPSPs were recorded after complete recovery of the membrane potential, we observed significantly enhanced IPSP amplitudes (IPSP pre-glutamate treatment: $8.4 \pm 0.12 \mathrm{mV}$ vs. IPSP $30 \mathrm{~min}$ after the recovery of membrane potential, $12.6 \pm 0.2 \mathrm{mV}$; Wilcoxon test, $\left.X^{2}=3.8, p<0.05, n=3\right)$.

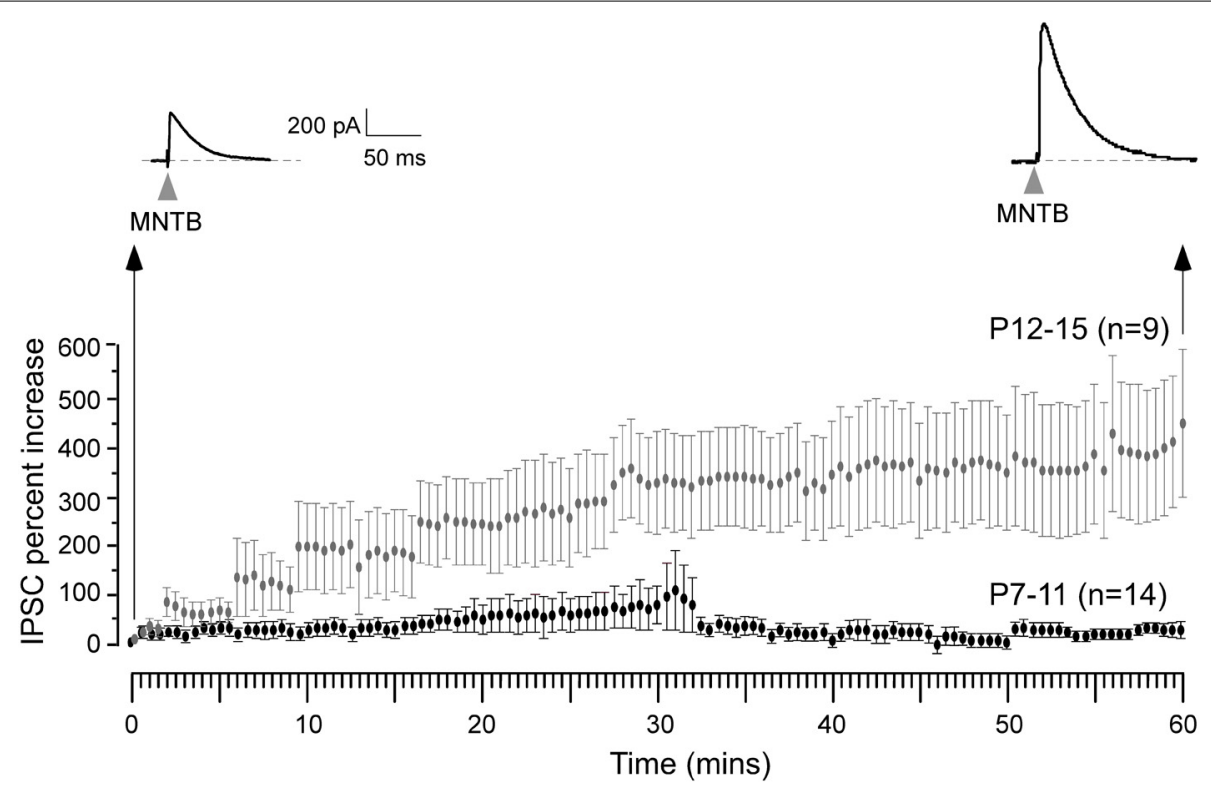

FIGURE 3 | Expression of iLTP is age-dependent. MNTB was continuously stimulated at $0.033 \mathrm{~Hz}$ for $1 \mathrm{~h}$ while voltage clamp recordings were obtained from the LSO neurons in the presence of ionotropic glutamate receptor antagonist kynuranic acid at $V_{\text {HOLD }}=0 \mathrm{mV}$. Under these circumstances, IPSCs were recorded as outward currents.
An IPSC recorded $1 \mathrm{~h}$ after this stimulation protocol shows a dramatic enhancement in its amplitude (top right trace) when compared to the initial IPSC (top left trace). Long-term potentiation of IPSCs was observed for neurons recorded at P12-15 (gray symbols), but not at P7-11 (black symbols). 


\section{VOLTAGE CLAMP RECORDINGS}

We then asked whether iLTP could be induced by stimulation of the MNTB afferents under voltage clamp conditions $\left(V_{\text {HOLD }}=0 \mathrm{mV}\right.$, ionotropic glutamate receptors blocked, thus in an absence of ipsilateral afferent stimulation) identical to the recording conditions employed for experiments in which iLTD was induced (Kotak and Sanes, 2000). For iLTD induction, we had used low frequency stimulation paradigm (LFS, $1 \mathrm{~Hz}$ for $15 \mathrm{~min}$ ) that led to long-term inhibitory depression for at least an hour. We could also induce and perturb iLTD in current clamp conditions using similar LFS regimen (Kotak et al., 2001). In pilot voltage clamp recordings when the MNTB was stimulated at a very low rate $(0.033 \mathrm{~Hz})$ to monitor baseline inhibitory strength we observed a small increase in IPSC amplitude. Therefore, we chose to carry out a full set of experiments using $0.033 \mathrm{~Hz}$. Continuous stimulation of the MNTB at $0.033 \mathrm{~Hz}$ produced a gradual increase in IPSC amplitude, and this enhancement became progressively larger during the recording session. As shown in Figure 3, neurons from P12-15 animals displayed a $\sim 400 \%$ increase in IPSC amplitude over the course of $1 \mathrm{hr}$, as compared to the initial baseline values (initial IPSC: $156 \pm 26 \mathrm{pA}$ vs. IPSC at $10 \mathrm{~min}$ of stimulation: $224 \pm 74$ $\mathrm{pA}$, Wilcoxon test, $X^{2}=5, p=0.02$; initial IPSC: $156 \pm 26 \mathrm{pA}$ vs. IPSC at $30 \mathrm{~min}$ of stimulation: $472 \pm 90, X^{2}=7.7, p=0.005$; initial IPSC: $156 \pm 26 \mathrm{pA}$ vs. IPSC at $60 \mathrm{~min}$ of stimulation: $495 \pm$ 94, $\left.X^{2}=8.7, p=0.003 ; n=9\right)$. When an identical stimulation protocol was employed on neurons from P7 to 11 animals, no significant change in IPSC amplitude was observed for up to $60 \mathrm{~min}$ (Figure 3). (Initial IPSC: $220 \pm 68 \mathrm{pA}$ vs. IPSC at $10 \mathrm{~min}$ of stimulation: $194 \pm 54 \mathrm{pA}$, IPSC at $30 \mathrm{~min}$ of stimulation: 227 $\pm 58 \mathrm{pA}$, IPSC at $60 \mathrm{~min}$ of stimulation: $198 \pm 67 \mathrm{pA}$, Wilcoxon test, $p>0.05$ for each comparison; $n=14$ ).

For controls, we have previously shown that the baseline of evoked IPSPs or IPSCs were stable through the entire $90 \mathrm{~min}$ recording session (see Figure 2 in Kotak and Sanes, 2000; Kotak et al., 2001). In the current study, whereas stimulation at $0.033 \mathrm{~Hz}$ produced robust iLTP after hearing onset, identical recording conditions and stimulation rates did not lead to any change in baseline sIPSCs before hearing onset (see Figure 3). Therefore, we did not perform additional controls. Voltage clamp recordings, similar to conditions in our previous iLTD studies (Kotak and Sanes, 2000; Chang et al., 2003), cells were held depolarized at $0 \mathrm{mV}$ and $4 \mathrm{mM}$ kynurenic acid was added to the ACSF ( $\mathrm{pH}$ 7.3 after bubbling with $\mathrm{O}_{2} / \mathrm{CO}_{2}$ ) to block ionotropic AMPA and NMDA receptors. Spontaneous IPSCs (sIPSC) too were recorded as outward currents before and after the stimulation protocol at $V_{\text {HOLD }}=0 \mathrm{mV}$. The very low frequency stimulation paradigm $(0.033 \mathrm{~Hz})$ was then applied continuously through the recording session $(1 \mathrm{~h})$ both to induce plasticity as well as acquire IPSCs.

To assess whether there was any alteration in the presynaptic release properties following the conditioning protocol, spontaneous IPSC (sIPSC) amplitude and frequency were monitored at early (initial $10 \mathrm{~min}$ ) and late $(60 \mathrm{~min})$ periods of the iLTP expression. As shown in Figure 4, these data indicate that iLTP was accompanied by a large increase in both the frequency and amplitude of spontaneous IPSCs (sIPSC amplitude before LTP: $6.3 \pm 1.8 \mathrm{pA}$ vs. sIPSC amplitude $60 \mathrm{~min}$ afterLTP: $61 \pm 19.5 \mathrm{pA}$; Wilcoxon test, $X^{2}=7.8, p<0.001$; sIPSC frequency before

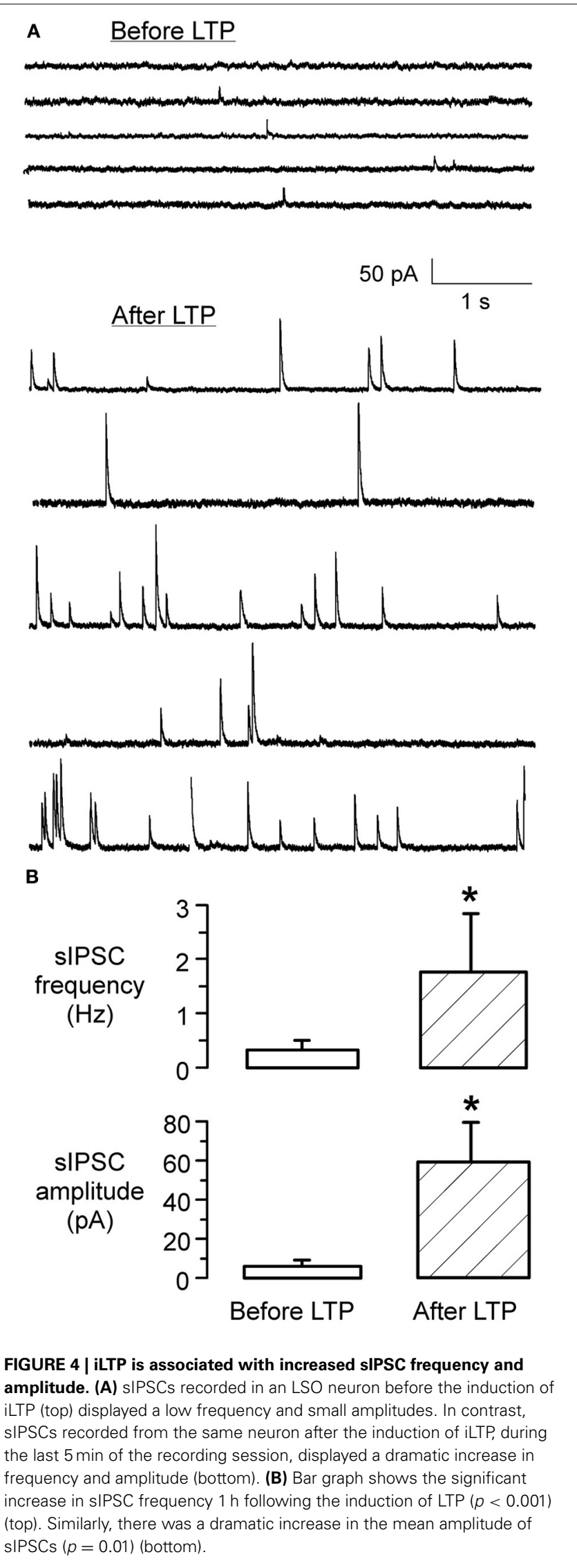


LTP: $0.28 \pm 0.14 \mathrm{~Hz}$ vs. sIPSC frequency $60 \mathrm{~min}$ after LTP: $1.76 \pm$ 1.2 Hz; Wilcoxon test, $\left.X^{2}=6.9, p=0.01\right)$. Further, $1 \mathrm{~h}$ after iLTP induction, MNTB-evoked IPSCs could not be de-potentiated using an MNTB afferent stimulation pattern (LFS, $1 \mathrm{~Hz}, 15 \mathrm{~min}$ ) previously shown to induce iLTD in naive slices (Kotak and Sanes, 2000). There was no significant difference between the IPSC amplitude at $60 \mathrm{~min}$ after LTP induction $(541 \pm 178 \mathrm{pA})$, as compared to the amplitude after an additional $15 \mathrm{~min}$ of $1 \mathrm{~Hz} / 15$ min stimulation $\left(531 \pm 163 \mathrm{pA}\right.$; Wilcoxon test, $X^{2}=1.6$, $p>0.1 ; n=3)$.

Our previous study showed that iLTD in the LSO requires the activation of $\mathrm{GABA}_{\mathrm{B}}$ receptors (Kotak et al., 2001). Therefore, we tested whether inhibitory LTP was also dependent on $\mathrm{GABA}_{B}$ receptor activation using a specific $\mathrm{GABA}_{\mathrm{B}}$ receptor antagonist (SCH-50911) during induction of inhibitory LTP in P1215 neurons. The MNTB was stimulated at the frequency that induced $\operatorname{iLTP}(0.033 \mathrm{~Hz})$ in voltage clamp condition $(\mathrm{Vh}=0 \mathrm{mV})$ while the slice was continuously exposed to $10 \mu \mathrm{M} \mathrm{SCH}-50911$ $(n=4)$. As shown in Figure 5, the mean IPSC amplitude over an hour period did not display a significant change (initial IPSC: $260 \pm 68 \mathrm{pA}$; IPSC at $60 \mathrm{~min}: 295 \pm 56 \mathrm{pA}$, Wilcoxon test, $\left.X^{2}=0.7, p=0.8, n=4\right)$. Thus, inhibitory LTP was blocked by the SCH compound.

\section{DISCUSSION}

The major finding of this study is that inhibitory MNTB synapses onto the LSO display an activity-dependent long-term

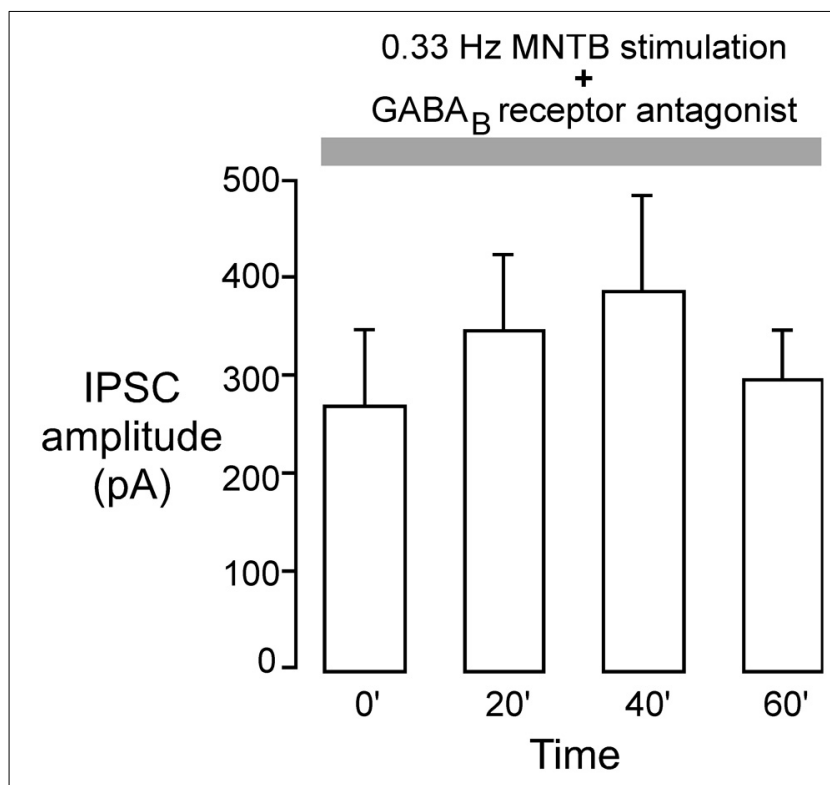

FIGURE 5 | GABA B receptor blockade perturbs inhibitory iLTP. MNTB was continuously stimulated at $0.033 \mathrm{~Hz}$ for $1 \mathrm{~h}$ while voltage clamp recordings were obtained from $\mathrm{P} 12$ to $15 \mathrm{LSO}$ neurons in the presence of an ionotropic glutamate receptor antagonist $\left(V_{\mathrm{HOLD}}=0 \mathrm{mV}\right)$. The $\mathrm{GABA}_{\mathrm{B}}$ receptor blocker, $\mathrm{SCH}-50911(10 \mu \mathrm{M})$, was present throughout the recordings. Under these conditions, IPSC amplitudes did not show any significant change toward potentiation. Each bar represents the mean current ( \pm s.e.m.) calculated at the beginning of the experiment, and at 20 , 40 , and $60 \mathrm{~min}$. potentiation (iLTP) following hearing onset (P12) but not prior to that. This contrasts with the induction of an equally robust iLTD before hearing onset (Kotak and Sanes, 2000). We do not imply that transition from no iLTD to iLTP occurs suddenly or precisely at hearing onset; rather, such plasticity mechanisms may develop gradually and may even become more pronounced during the several weeks thereafter as sound coding properties associated with ILD are consolidated in the LSO. We had proposed that iLTD before hearing onset may underlie the elimination of redundant inhibitory synapses in LSO and MSO (Sanes and Siverls, 1991; Sanes and Takàcs, 1993; Kotak and Sanes, 2000; Kapfer et al., 2002; Kim and Kandler, 2003). Even as the numbers of inhibitory boutons per axon are decreased (Sanes and Takàcs, 1993), the strength of individual existing connections becomes much stronger as revealed by the increase in the amplitude of inhibitory events (Sanes, 1993; Kim and Kandler, 2003). Therefore, we propose that the emergence of iLTP may be one form of plasticity to support inhibitory synapse stabilization and strengthening in vivo.

When coupled with MNTB stimulation, either postsynaptic depolarization alone, or activation of ipsilateral excitatory afferents alone, was not sufficient to induce iLTP under current clamp conditions. We propose two mechanisms that could mediate iLTP in an intact developing animal. First, sufficient postsynaptic depolarization could result from the synergistic activity of developing excitatory terminals and/or the co-release of glutamate from the MNTB terminals themselves (Gillespie and Kandler, 2005; Case and Gillespie, 2011; Alamilla and Gillespie, 2013). Second, it is possible that very low levels of glutamatergic afferent activity can activate postsynaptic metabotropic glutamate receptors, which trigger prolonged depolarizations and calcium entry by low levels of synaptic activity (Kotak and Sanes, 1995; Ene et al., 2003) that may be sufficient to support iLTP. This is consistent with our observation that IPSPs could be potentiated by the direct application of glutamate that may have led to calcium influx via activation of ionotropic as well as metabotropic glutamate receptors (Figure 2).

Our previous results have shown that $G_{A B A}$ receptors are involved in the generation of iLTD (Kotak et al., 2001). Similarly, it appears that $\mathrm{GABA}_{\mathrm{B}}$ receptors are involved in iLTP. Both sets of experiments were performed in voltage clamp conditions where the internal recording solution contained QX-314, which blocks the postsynaptic $\mathrm{GABA}_{\mathrm{B}}$ receptor-gated $\mathrm{K}^{+}$channel (Nathan et al., 1990; Andrade, 1991). The fact we did not observe iLTP in the presence of a selective antagonist ( $\mathrm{SCH}-50911)$ could be consistent with either pre- or postsynaptic $\mathrm{GABA}_{\mathrm{B}}$ receptor signaling (Figure 5). One reason for this is that blockade of the $\mathrm{GABA}_{\mathrm{B}}$ receptor-gated potassium conductance by QX-314 in the pipette solution leaves open the possibility that other second messengers are involved (Kotak et al., 2001). In addition, the increase in sIPSC frequency that occurs during iLTP (Figure 4) suggests that a presynaptic mechanism may accompany postsynaptic strengthening.

The adjustments of auditory neuron response properties to dynamic range, frequency, or sound location during early life may well depend on activity-dependent synaptic plasticity mechanisms (Sanes and Constantine-Paton, 1983, 1985; Knudsen et al., 1984; Joseph and Hyson, 1993; Zhang et al., 2001; 
Magnusson et al., 2008). For mature LSO principal neurons to properly compute ILDs, the excitatory and inhibitory synapses must become precisely matched along the tonotopic axes during development (Moore and Caspary, 1983; Spangler et al., 1985; Cant and Casseday, 1986; Sanes and Rubel, 1988; Glendenning et al., 1991; Sanes and Siverls, 1991). Our observations raise the possibility that increased inhibitory synapse strength may permit these to stabilize during the time when specificity is achieved in vivo.

\section{AUTHOR CONTRIBUTIONS}

Vibhakar C. Kotak and Dan H. Sanes conceived and designed the experiments, Vibhakar C. Kotak performed the experiments and analyzed the data, and Vibhakar C. Kotak and Dan H. Sanes wrote the paper.

\section{REFERENCES}

Aizenman, C. D., Manis, P. B., and Linden, D. J. (1998). Polarity of longterm synaptic gain change is related to postsynaptic spike firing at a cerebellar inhibitory synapse. Neuron 21, 827-835. doi: 10.1016/S0896-6273(00) 80598-X

Alamilla, J., and Gillespie, D. C. (2013). Maturation of calcium-dependent GABA, glycine, and glutamate release in the glycinergic MNTB-LSO pathway. PLoS ONE 8:e75688. doi: 10.1371/journal.pone.0075688

Andrade, R. (1991). Blockade of neurotransmitter-activated K conductance by QX314 in the rat hippocampus. Eur. J. Pharmacol. 199, 259-262. doi: 10.1016/00142999(91)90467-5

Bear, M., and Malenka, R. C. (1994). Synaptic plasticity: LTP and LTD. Curr. Opin. Neurobiol. 4, 389-400. doi: 10.1016/0959-4388(94)90101-5

Bliss, T. V. P., Collingridge, G. L., and Morris, R. G. M. (2013). Synaptic plasticity in health and disease: introduction and overview. Philos. Trans. R. Soc. Lond. B Biol. Sci. 369, 20130129. doi: 10.1098/rstb.2013.0129

Boudreau, J. C., and Tsutchitani, C. (1968). Binaural interaction the cat superior olive s-segment. J. Neurophysiol. 31, 442-454.

Caird, D., and Klinke, R. (1983). Processing of binaural stimuli by cat superior olivary complex neurons. Exp. Brain Res. 52, 385-399. doi: 10.1007/BF002 38032

Cant, N. B., and Casseday, J. H. (1986). Projections from the anteroventral cochlear nucleus to the lateral and medial superior olivary nuclei. J. Comp. Neurol. 247, 457-476. doi: 10.1002/cne.902470406

Case, D. T., and Gillespie, D. C. (2011). Pre- and postsynaptic properties of glutamatergic transmission in the immature inhibitory MNTB-LSO pathway. J. Neurophysiol. 106, 2570-2579. doi: 10.1152/jn.00644.2010

Chang, E. H., Kotak, V. C., and Sanes, D. H. (2003). Long-term depression of synaptic inhibition is expressed postsynaptically in the developing auditory system. J. Neurophysiol. 90, 1479-1488. doi: 10.1152/jn.00386.2003

Ene, F. A., Kullman, P. H., Gillespie, D. C., and Kandler, K. (2003). Glutamatergic calcium responses in the developing lateral superior olive: receptor types and their specific activation by synaptic activity patterns. J. Neurophys. 90, 2581-2591. doi: 10.1152/jn.00238.2003

Gillespie, D. C., and Kandler, K. (2005). Inhibitory synapses in the developing auditory system are glutamatergic. Nat. Neurosci. 8, 332-338. doi: 10.1038/ nn 1397

Glendenning, K. K., Masterton, R. B., Baker, B. N., and Wenthold, R. J. (1991). Acoustic chiasm. III: Nature, distribution, and sources of afferents to the lateral superior olive in the cat. J. Comp. Neurol. 310, 377-400. doi: $10.1002 /$ cne. 903100308

Harnischfeger, G., Neuweiler, G., and Schlegel, P. (1985). Interaural time and intensity coding in superior olivary complex and inferior colliculus of the echo locating bat Molossus ater. J. Neurophysiol. 53, 89-109.

Joseph, A. W., and Hyson, R. L. (1993). Coincidence detection by binaural neurons in the chick brain stem. J. Neurophysiol. 69, 1197-1211.

Kandler, K. (2004). Activity-dependent organization of inhibitory circuits: lessons from the auditory system. Curr. Opin. Neurobiol. 14, 96-104. doi: 10.1016/j.conb.2004.01.017
Kandler, K., Clause, A., and Jihyun, N. J. (2009). Tonotopic reorganization of developing auditory brainstem circuits. Nat. Neurosci. 12, 711-717. doi: $10.1038 / \mathrm{nn} .2332$

Kandler, K., and Gillespie, D. C. (2005). Developmental refinement of inhibitory sound-localization circuits. TINS 28, 290-296. doi: 10.1016/j.tins.2005.04.007

Kapfer, C., Seidl, A. H., Schweizer, H., and Grothe, B. (2002). Experiencedependent refinement of inhibitory inputs to auditory coincidence-detector neurons. Nat. Neurosci. 5, 247-253. doi: 10.1038/nn810

Kim, G., and Kandler, K. (2003). Elimination and strengthening of glycinergic/GABAergic connections during tonotopic map formation. Nat. Neurosci. 6, 282-290. doi: 10.1038/nn1015

Knudsen, E. I., Esterly, S. D., and Knudsen, P. F. (1984). Monaural occlusion alters sound localization during a sensitive period in the barn owl. J. Neurosci. 4, 1001-1011.

Komatsu, Y. (1994). Age-dependent long-term potentiation of inhibitory synaptic transmission in rat visual cortex. J. Neurosci. 14, 6488-6499.

Komatsu, Y. (1996). GABA $\mathrm{B}$ receptors, monoamine receptors, and postsynaptic inositol trisphosphate-induced $\mathrm{Ca}^{2+}$ release are involved in the induction of long-term potentiation at visual cortical inhibitory synapses. J. Neurosci. 16, 6342-6352.

Komatsu, Y., and Iwakiri, M. (1993). Long-term modification of inhibitory synaptic transmission in developing visual cortex. Neuroreport 4, 907-910. doi: 10.1097/00001756-199307000-00017

Komatsu, Y., and Yoshimura, Y. (2000). Activity-dependent maintenance of long-term potentiation at visual cortical inhibitory synapses. J. Neurosci. 15, 7539-7546.

Kotak, V. C., DiMattina, C., and Sanes, D. H. (2001). GABA(B) and Trk receptor signaling mediates long-lasting inhibitory synaptic depression. J. Neurophysiol. 86, 536-540.

Kotak, V. C., Fujisawa, S., Lee, F. A., Karthikeyan, O., Aoki, C., and Sanes, D. H. (2005). Hearing loss raises excitability in the auditory cortex. J. Neurosci. 25, 3908-3918. doi: 10.1523/JNEUROSCI.5169-04.2005

Kotak, V. C., Korada, S., Schwartz, I. R., and Sanes, D. H. (1998). A developmental shift from GABAergic to glycinergic transmission in the central auditory system. J. Neurosci. 18, 4646-4655.

Kotak, V. C., and Sanes, D. H. (1995). Synaptically evoked prolonged depolarizations in the developing auditory system. J. Neurophysiol. 74, 1611-1620.

Kotak, V. C., and Sanes, D. H. (1997). Deafferentation of glutamatergic afferents weakens synaptic strength in the developing auditory system. Eur. J. Neurosci. 9, 2340-2347.

Kotak, V. C., and Sanes, D. H. (2000). Long-lasting inhibitory synaptic depression is age- and calcium-dependent. J. Neurosci. 20, 5820-5826.

Kotak, V. C., and Sanes, D. H. (2002). Postsynaptic kinase signaling underlies inhibitory synaptic plasticity in the lateral superior olive. J. Neurobiol. 53, 36-43. doi: 10.1002/neu.10107

Magnusson, A. K., Park, T. J., Pecka, M., Grothe, B., and Koch, U. (2008). Retrograde GABA signaling adjusts sound localization by balancing excitation and inhibition in the brainstem. Neuron 59, 125-137. doi: 10.1016/j.neuron.2008.05.011

Moore, D. R., Kotak, V. C., and Sanes, D. H. (1998). Commissural and lemniscal synaptic input to the gerbil inferior colliculus. J. Neurophysiol. 80, 2229-2236.

Moore, M. J., and Caspary, D. M. (1983). Strychnine blocks binaural inhibition in lateral superior olivary neurons. J. Neurosci. 3, 237-242.

Morishita, W., and Sastry, B. R. (1996). Postsynaptic mechanisms underlying longterm depression of GABAergic transmission in neurons of the deep cerebellar nuclei. J. Neurophysiol. 76, 59-68.

Nathan, T., Jensen, M. S., and Lambert, J. D. (1990). The slow inhibitory postsynaptic potential in rat hippocampal CA1 neurones is blocked by intracellular injection of QX-314. Neurosci. Lett. 110, 309-313. doi: 10.1016/0304-3940(90) 90865-7

Oda, Y., Charpier, S., Murayama, Y., Suma, C., and Korn, H. (1995). Long-term potentiation of glycinergic inhibitory synaptic transmission. J. Neurophysiol. 74, 1056-1074.

Oda, Y., Kawasaki, K., Morita, M., Korn, H., and Matsui, H. (1998). Inhibitory longterm potentiation underlies auditory conditioning of goldfish escape behavior. Nature 394, 182-185. doi: 10.1038/28172

Ouardouz, M., and Sastry, B. R. (2000). Mechanisms underlying LTP of inhibitory synaptic transmission int he deep cerebellar nuclei. J. Neurophysiol. 84, 1414-1421. 
Sanes, D. H. (1993). The development of synaptic function and integration in the central auditory system. J. Neurosci. 13, 2627-2637.

Sanes, D. H., and Constantine-Paton, M. (1983). Altered activity patterns during development reduce neural tuning. Science 221, 1183-1185. doi: 10.1126/science.6612332

Sanes, D. H., and Constantine-Paton, M. (1985). The development of stimulus following the cochlear nerve and inferior colliculus of the mouse. Brain Res. 354, 255-267. doi: 10.1016/0165-3806(85)90177-4

Sanes, D. H., and Friauf, E. (2000). Development and influence of inhibition in the lateral superior olivary nucleus. Hear. Res. 147, 46-58. doi: 10.1016/S03785955(00)00119-2

Sanes, D. H., and Rubel, E. W. (1988). The ontogeny of inhibition and excitation in the gerbil lateral superior olive. J. Neurosci. 8, 682-700.

Sanes, D. H., and Siverls, V. (1991). Development and specificity of inhibitory terminal arborizations in the central nervous system. J. Neurobiol. 22, 837-854. doi: 10.1002/neu.480220805

Sanes, D. H., and Takàcs, C. (1993). Activity-dependent refinement of inhibitory connections. Eur. J. Neurosci. 5, 570-574. doi: 10.1111/j.14609568.1993.tb00522.x

Spangler, K. M., Warr, W. B., and Henkel, C. K. (1985). The projections of principal cells of the medial nucleus of the trapezoid body in the cat. J. Comp. Neurol. 238, 249-262. doi: 10.1002/cne.9023 80302

Sterenborg, J. C., Pilati, N., Sheridan, C. J., Uchitel, O. D., Forsythe, I. D., and Barnes-Davies, M. (2010). Lateral olivocochlear (LOC) Neurons of the mouse LSO receive excitatory and inhibitory synaptic inputswith slower kinetics than LSO principal neurons. Hear. Res. 270, 119-126. doi: 10.1016/j.heares.2010.08.013

Tollin, D. J. (2003). The lateral superior olive: a functional role in sound source localization. Neuroscientist 9, 127-143. doi: 10.1177/1073858403252228

Walcher, J., Hassfurth, B., Grothe, B., and Koch, U. (2011). Comparative posthearing development of inhibitory inputs to the lateral superior olive in gerbils and mice. J. Neurophysiol. 106, 1443-1453. doi: 10.1152/jn.01087.2010

Zhang, L., Bao, S., and Merzenich, M. M. (2001). Persistent and specific influences of early acoustic environments on primary auditory cortex. Nat. Neurosci. 4, 1123-1130. doi: 10.1038/nn745

Conflict of Interest Statement: The authors declare that the research was conducted in the absence of any commercial or financial relationships that could be construed as a potential conflict of interest.

Received: 12 March 2014; accepted: 02 June 2014; published online: 19 June 2014. Citation: Kotak VC and Sanes DH (2014) Developmental expression of inhibitory synaptic long-term potentiation in the lateral superior olive. Front. Neural Circuits 8:67. doi: 10.3389/fncir.2014.00067

This article was submitted to the journal Frontiers in Neural Circuits.

Copyright (C) 2014 Kotak and Sanes. This is an open-access article distributed under the terms of the Creative Commons Attribution License (CC BY). The use, distribution or reproduction in other forums is permitted, provided the original author(s) or licensor are credited and that the original publication in this journal is cited, in accordance with accepted academic practice. No use, distribution or reproduction is permitted which does not comply with these terms. 